University of Rhode Island

DigitalCommons@URI

Open Access Master's Theses

2013

\title{
Locus of Control as a Predictor of Maternal Feeding Style
}

Anna G. Lubiner

University of Rhode Island, alubiner@my.uri.edu

Follow this and additional works at: https://digitalcommons.uri.edu/theses

Recommended Citation

Lubiner, Anna G., "Locus of Control as a Predictor of Maternal Feeding Style" (2013). Open Access

Master's Theses. Paper 67.

https://digitalcommons.uri.edu/theses/67

This Thesis is brought to you for free and open access by DigitalCommons@URI. It has been accepted for inclusion in Open Access Master's Theses by an authorized administrator of DigitalCommons@URI. For more information, please contact digitalcommons-group@uri.edu. 
LOCUS OF CONTROL AS A PREDICTOR OF MATERNAL FEEDING STYLE BY

ANNA G. LUBINER

THESIS SUBMITTED IN PARTIAL FULFILLMENT OF THE REQUIREMENTS

FOR THE DEGREE OF MASTER OF ARTS IN PSYCHOLOGY

UNIVERSITY OF RHODE ISLAND

2013 


\section{MASTER OF ARTS THESIS}

OF

ANNA G. LUBINER

APPROVED:

Thesis Committee:

$\begin{array}{ll}\text { Major Professor: } & \text { Kathleen S. Gorman } \\ & \text { Alison Tovar } \\ & \text { Margaret R. Rogers } \\ & \text { Nasser H. Zawia } \\ & \text { DEAN OF THE GRADUATE SCHOOL }\end{array}$

UNIVERSITY OF RHODE ISLAND

2013 


\begin{abstract}
The purpose of this study was twofold: To investigate the association between parental feeding styles (authoritarian, authoritative and permissive) and maternal locus of control orientation, and to determine whether depression moderated the relationship between feeding style and locus of control. Participants were 68-English speaking mothers of preschool age children (3 to 5), who participated in two previous studies. Measures of parental feeding style, maternal depression, and locus of control, as well as basic demographic data were drawn from larger interview batteries administered as part of the previous studies.

It was hypothesized that a more internal locus of control orientation would be associated with an authoritative feeding style, while a more external locus of control would be associated with permissive and authoritarian feeding styles. Depression was expected to moderate the relationship between a more external locus of control and authoritarian and permissive feeding styles, such that an external locus of control would be associated with authoritarian feeding style when levels of depression were lower and a permissive feeding style when levels of depression were higher.

Contrary to hypotheses, a permissive feeding style was associated with a more internal locus of control. No association was found between locus of control and authoritarian or authoritative feeding styles. Additionally, no feeding style was associated with depression. It is suggested that future research examine the bidirectional nature of the parent-child relationship and its affects on maternal locus of control and feeding style.
\end{abstract}




\section{Acknowledgments}

I would like to express a special thank you to my major professor, Dr. Kathleen Gorman. Kathleen has been an incomparable mentor and guide; she has encouraged my intellectual curiosity, honed my critical thinking skills and taught me to write like researcher. I am grateful to Kathleen for her patience, support, and encouragement, which have been vital to my success.

I would also like to thank my committee members Dr. Margaret Rogers, Dr. Alison Tovar and Chair, Dr. Diane Martins. In particular, I would like to thank Dr. Margaret Rogers for her encouragement, enthusiasm and guidance through this process;

Dr. Alison Tovar for her advice and suggestions relative to my research, and her software recommendations; and Dr. Diane Martins for taking the time to meet with me to discuss my research and for serving as chair of my defense committee. Additionally, I would like to thank Dr. Kathleen Gorman and Dr. Karen McCurdy for the use of their data. Finally, I would like to thank my friends and family who have cheered and supported me throughout this journey. Most especially, I would like to thank my father, Joseph Lubiner, for his endless encouragement, editorial consult, and unconditional love and support. 


\section{Table of Contents}

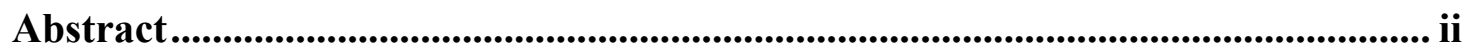

Acknowledgements....................................................................................... iii

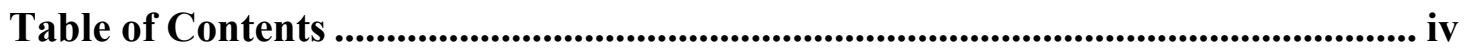

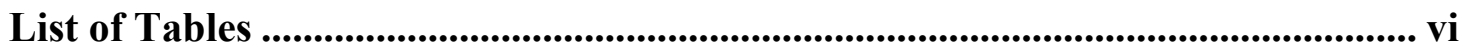

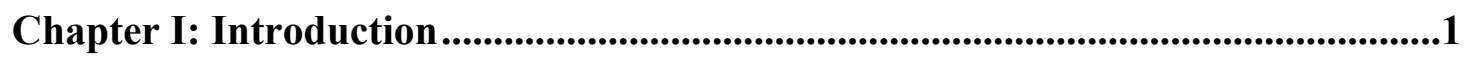

Statement of the Problem ............................................................................ 1

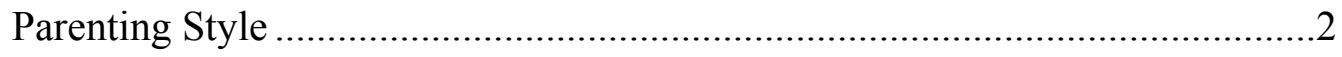

Parental Feeding Style ......................................................................

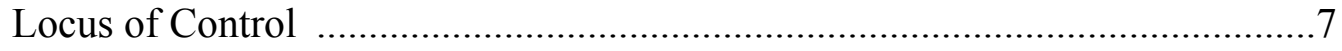

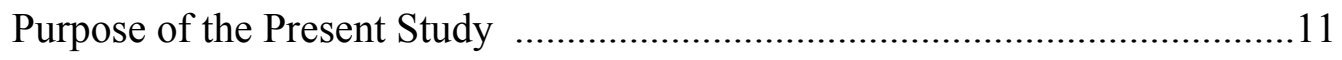

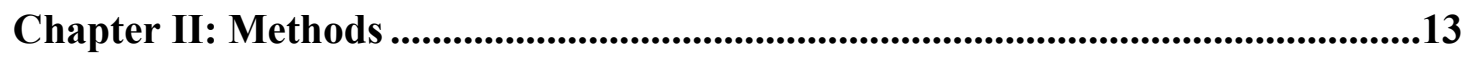

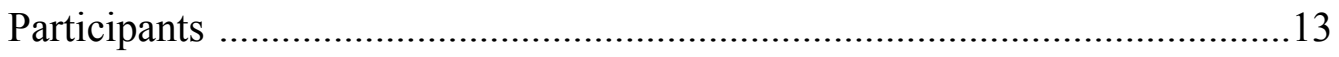

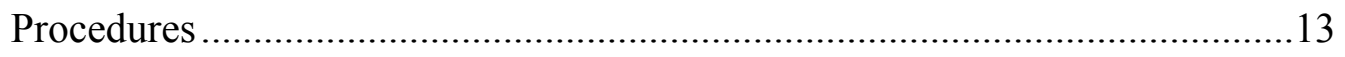

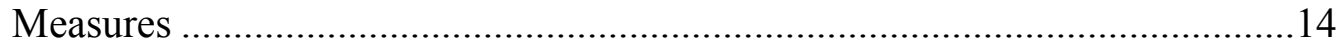

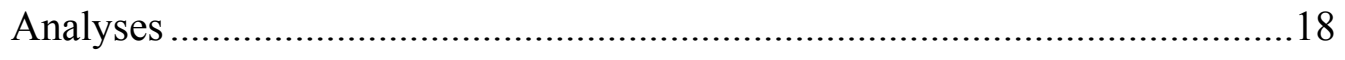




\section{Table of Contents (Continued)}

Chapter III: Results

Descriptive Statistics .20

Covariate Analyses

Locus of Control and Parental Feeding Styles....

Locus of Control, Parental Feeding Styles, and Maternal Depression

Chapter IV: Discussion...............................................................................................30

Limitations

Future Direction and Conclusions.

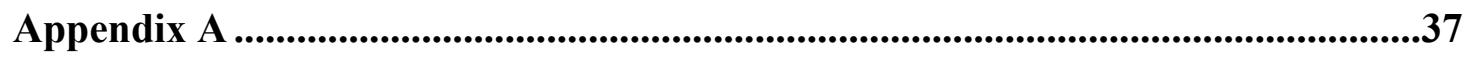

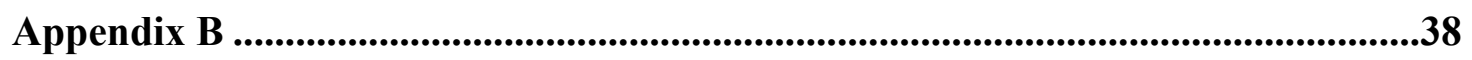

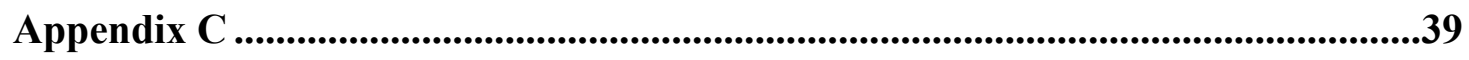

Appendix D .........................................................................................................41

Appendix $E$.......................................................................................................................42

References .................................................................................................................43 


\section{List of Tables}

Table

Page

Table 1. Participant Characteristics

Table 2. Descriptive statistics: Parental feeding styles, locus of control and depression

Table 3. Pearson product-moment correlations: Parental feeding style, locus of control, depression and demographic variables

Table 4. Pearson product-moment correlations: Parental feeding styles, locus of control, and depression

Table 5. Hierarchical linear regression: Permissive feeding 27 style

Table 6. Hierarchical linear regression: Authoritarian feeding style

Table 7. Hierarchical linear regression: Authoritative feeding style 


\section{Chapter I: Introduction}

\section{Statement of the Problem}

Childhood obesity is reaching epidemic proportions in the United States. Since 1980, the childhood obesity rate has almost tripled, making it a primary public health concern. Almost 17\% (12.5 million) of children ages 2 to19 are considered obese, and nearly one-third of preschool age children are obese or overweight (Centers for Disease Control and Prevention, 2012). Childhood obesity is associated with a host of negative health outcomes, including Type 2 diabetes, hypertension, respiratory problems, and depression. Furthermore, obesity in childhood is associated with obesity and overweight in adolescence and adulthood (Wieting, 2008). Minority and low-income populations are disproportionality affected by the rising obesity rates (Centers for Disease Control and Prevention, 2012).

The etiology of childhood obesity is multifaceted; most often, it is the result of a constellation of factors related to biology and environment (Gregory, Paxton, \& Brozovic, 2010). The increase in prevalence rates, particularly among lowincome populations, suggests environment features prominently in the development of childhood obesity (Ogden, Carroll, Curtin, Lamb, \& Flegal, 2010). Limited access to healthy affordable foods, the availability and consumption of high-calorie low-nutrient foods, and physical inactivity, have been associated with increasing childhood obesity rates (Centers for Disease Control and Prevention, 2012).

While these factors certainly influence child weight and food preferences, parents appreciably affect child food consumption behaviors, particularly for young 
children (Kröller \& Warschburger, 2008). Since young children rely almost exclusively on their primary caregivers, most often mothers, to provide food, maternal influence is an important area of inquiry in the study of the causes of childhood obesity (Patrick, Nicklas, Hughes, \& Morales, 2005).

\section{Parenting Style}

There is little debate that parents exert significant influence over the developmental trajectory of children. Parenting style, often used as a proxy to examine parental functioning and parental influence, refers to patterns of parental behaviors and attitudes that remain relatively consistent across time and setting. One of the most prominent theories of parental style employs a two-dimensional framework that classifies several combinations of distinctive forms of parental demandingness and parental responsiveness. Within this model, parental demandingness relates to behavioral expectations and behavioral control over the child, while parental responsiveness refers to levels of warmth and sensitivity to the child's needs (Ventura \& Birch, 2008). This taxonomy of parental style, developed by Baumrind (1971) and extended by Maccoby and Martin (1983), includes four types of parenting styles: authoritarian (high demandingness, low responsiveness), authoritative (high demandingness, high responsiveness), permissive (low demandingness, high responsiveness), and neglectful (low demandingness, low responsiveness).

The extant literature suggests that parenting style is linked to a variety of child outcomes, including cognitive, socioemotional, and health related functioning (Ventura \& Birch, 2008). Several studies found positive associations between 
authoritative parenting style and enhanced socioemotional and cognitive outcomes in children and adolescents (Baumrind, 1991; Weiss \& Schwarz, 1996). Researchers posit authoritative parenting style encourages children to develop selfregulation and self-evaluative skills (Darling \& Steinberg, 1993; Grolnick \& Ryan, 1989). There are, however, a number of studies that suggest that parenting style and the associated outcomes are population specific. For example, in studies conducted with low-income African-American children, authoritarian parenting style was associated with better outcomes (Lamborn, Dornbusch, \& Steinberg, 1996; Baldwin, Baldwin, \& Cole, 1990). It is hypothesized that in high-crime urban communities, authoritarian parenting style serves as a protective factor (Lamborn et al., 1996).

Differences in findings highlight the importance of contextualizing parenting style. Parenting style is influenced by a variety of factors including, socioeconomic status, ethnic and cultural identity, individual characteristics such as personality and psychopathology, as well as characteristics of the child (Kendler, Sham, \& MacLean, 1997). Therefore, it is expected that parenting style and the related child outcomes will vary between individuals and across populations.

\section{Parental Feeding Style}

Previous research has demonstrated a relationship between parenting style and childhood obesity (Rhee, Lumeng, Appugliese, Kaciroti, \& Bradley, 2006). However, understanding the processes by which parenting style affects childhood obesity outcomes has been limited and measurement imprecise (Hoerr et al., 2009). Hughes and colleagues (2005) addressed this issue by adapting Baumrind's 
parenting style paradigm and applying it to the feeding domain. Like parenting style, parental feeding style is a two dimensional framework that identifies several amalgamations of demandingness and responsiveness, resulting in a typology of parental feeding style that includes authoritarian, authoritative, indulgent and uninvolved styles. Authoritarian feeding style (high demandingness, low responsiveness) exerts directive control, manifested as pressure to eat and/or food restriction, using rewards and punishments, and rigid adherence to food consumption rules, irrespective of child need or preference. Authoritative feeding style (high demandingness, high responsiveness) applies nondirective control practices to feeding, expressed through clear, though adaptable, behavioral and food consumption expectations; it is associated with parental feeding behaviors that include modeling, encouragement, reasoning, and structured child choice. Indulgent feeding style (low demandingness, high responsiveness) and uninvolved feeding style (low demandingness, low responsiveness), apply little or no control over child food consumption behaviors (i.e., the child eats whatever s/he wants) with varying levels of parental acceptance and interaction.

Several studies found positive relationships between authoritative feeding style and healthier child weight (Moens, Braet, \& Soetens, 2007; Rhee et al., 2006), as well as the increased availability and consumption of fruits and vegetables (Moens et al., 2007; Patrick et al., 2005). Like authoritative parenting style, authoritative feeding style is thought to foster self-regulation and self-monitoring behaviors, by encouraging children to attend to their own feelings of hunger and satiety (Polfuss \& Frenn, 2012). Furthermore, nondirective control may foster 
feelings of competence in children, in part because they are unaware of the parental direction. For example, a parent offers nondirective control by making specific foods available in the home and allowing the child to decide what s/he would like to eat. The parent manages the food environment but offers little directive control, encouraging the child to make his/her own choices about what to eat (Ogden, Reynolds, \& Smith, 2006).

Authoritarian feeding style has been associated with overeating and poor food regulation in children (Faith, Scanlon, Birch, Francis, \& Sherry, 2004; Hughes et al., 2006; Rhee et al., 2006). One explanation for this phenomenon is that children of parents with an authoritarian feeding style are more likely to over consume foods that are restricted, often high fat and high sugar foods, when given the opportunity (Patrick et al., 2005; Savage, Fisher, \& Birch, 2007). Additionally, excessive directive control around feeding is thought to disrupt children's own physiological cues and they are therefore less likely to recognize when they are sated (Polfuss \& Frenn, 2012). Notably, pressure to eat, another feature of authoritarian feeding style, has been associated with lower adiposity in children (Carnell \& Wardle, 2007; Spruijt-Metz et al., 2002). Researchers suggest 'pressure to eat' is related to maternal perceptions regarding child underweight and undernourishment. This population of children, therefore, is more likely to be of healthy weight (Webber, Hill, Cooke, Carnell, \& Wardle, 2010).

Indulgent feeding style makes few demands on children. When direction is offered, it is delivered with warmth and support. Indulgent feeding style in particular, has been associated with increased adiposity in children (Moens et al., 
2007), especially children in low-income, minority (Hughes, Shewchuck, Baskin, Nicklas, \& Qu, 2008) and immigrant populations (Tovar et al., 2012). One explanation for this association may be that disadvantaged populations use food as a relatively affordable means of comfort for children living in high stress environments (Hughes, et al, 2008).

Uninvolved feeding style, low demandingness and low responsiveness, is associated with the lower levels of fruit consumption in preschool age children (Hoerr et al., 2009). It has been suggested that uninvolved feeding style is related to increased child weight (Savage et al., 2007), though this has not been supported in the literature. Indulgent feeding style and uninvolved feeding style are often grouped together and reported as a permissive feeding style (Blissett, 2011; Hoerr et al., 2009), which may account for the limited outcome data specifically related to uninvolved feeding style.

Like parenting style, parental feeding style is shaped by multiple factors that exist across a variety of systems (i.e. individual, family, neighborhood, society). A fair amount of research has been conducted examining the social context (i.e., ethnicity, culture, socioeconomic status) and its effect on parental feeding style (e.g., Tovar et al., 2012, Hoerr et al., 2009; Hughes et al., 2008; Hughes et al., 2006). Several studies have found feeding style differs among mothers of different socio-economic groups, with lower SES mothers more likely to engage in authoritarian or permissive feeding style behaviors (Clark et al., 2009; Feinberg et al., 2008; Saxton et al., 2009). Additionally, Feinberg and colleagues (2008) found that food insecure mothers were more likely to restrict food or 
pressure their children to eat, behaviors associated with an authoritarian feeding style, than their food secure counterparts. Further, researchers examining cultural variations in feeding across groups found differences in parental feeding styles between groups. For example, Hughes and colleagues (2006) identified cultural feeding style differences in a group of low-income parents, with Hispanic parents more likely to engage in authoritarian or indulgent feedings styles, than their African-American counterparts. Finally, young maternal age, low educational attainment and single parenthood status may also be factors that affect feeding style. In a recent study, Hurley, Black, Caulfield and Papas (2008) found in a group of young mothers with low educational attainment, those who were single were more likely to engage in authoritarian feeding style behaviors, while their partnered counterparts were more likely to engage in indulgent feeding style behaviors.

Though the research has identified similarities across and within specific populations and cultures, there still exist significant individual differences associated with parental feeding style. Researchers have begun to examine the relationship between maternal characteristics (i.e., maternal psychological health, expectations and beliefs about parenting, and parenting satisfaction) and parental feeding style (Mitchell, Brennan, Hayes, \& Miles, 2009; Topham et al., 2010), in an effort to identify and account for individual variation. One factor that has received little attention and may account for some intraindividual differences related to maternal feeding style is locus of control orientation.

\section{Locus of Control}

Locus of control orientation refers to the degree to which an individual feels 
that events and/or outcomes are the result of his/her behavior and actions or the result of mechanisms outside of his/her sphere of influence or control. Developed by Rotter (1966), the locus of control construct is based on social learning theory, which conceptualizes behavior as an interaction between reinforcement and contingencies. A person's locus of control orientation is based on individual perceptions of these reinforcements and the degree to which reinforcements are the result of personal behavior (internal) or the result of fate or luck (external) (Kormanik \& Rocco, 2009). Rotter (1966) conceived the locus of control measure as a generalizable tool with predictive value that provides information about expected behaviors based on intraindividual characteristics and the interaction of those characteristics with the environment.

While there is very little research on the relationship between locus of control orientation and feeding style specifically, there is support for a relationship between parenting style and locus of control orientation. In general, the literature suggests that parents with a more external locus of control orientation approach childrearing differently than parents with a more internal locus of control orientation (Campis, Lyman, \& Prentice-Dunn, 1986). Specifically, a more internal locus of control orientation has been associated with perceptions of parental selfefficacy and influence over the child's behavior and development (Campis et al., 1986; Hagekull, Bohlin, \& Hammarberg, 2001; Harris \& Nathan, 1973). As a result, parents with a more internal locus of control orientation are more likely to engage in parenting behaviors that employ reason and appeal to the child's own decision making skills, behaviors associated with an authoritative parenting style 
(Hagekull et al., 2001; Janssens, 1994).

In contrast, the research on external locus of control orientation and parenting style is mixed; findings suggest associations to authoritarian (Bugental, Caporael, \& Shennum, 1980; Hagekull et al., 2001; Janssens, 1994; McGroder, 2000) as well as permissive and neglectful parenting styles (Coyne \& Thompson, 2011; Freed \& Tompson, 2011; Gerdes et al., 2007). A more external locus of control orientation, specific to childrearing, may be related to a lack of perceived control over the child's behavior and development (Campis et al., 1986; Harris \& Nathan, 1973). The literature suggests that some parents respond to this perception by trying to exert control and demanding high levels of compliance and self-control from the child, behaviors associated with an authoritarian parenting style (Hagekull et al., 2001; Janssens, 1994). While other parents, may feel ineffectual and helpless, and respond to this perception by adopting a more permissive or neglectful parenting style (Leung \& Slep, 2006).

Researchers theorize that differences in parenting style, related to a more external locus of control orientation, may be affected by the presence or absence of mediating or moderating variables. Socio-demographic factors such as lower SES, minority status and low educational attainment have all been linked to parenting style (e.g. Hughes et al., 2006; Hurley et al 2008) and a more external locus of control (Banks, 1988; Cole \& Garner, 1986). In addition to these sociodemographic variables some researchers suggest the relationship between external locus of control and parenting style may also be affected by maternal depression, whereby depressed mothers with a more external locus control orientation, are 
more likely to employ a permissive or neglectful parenting style (Gerdes et al., 2007; Leung \& Slep, 2006) than non-depressed mothers. Supporting these recent findings is previous research that found depression to be associated with a more external locus of control orientation (Prociuk, Breen, \& Lussier, 1976), and, in separate studies, depression to be associated with permissive or neglectful parenting style (Aunola, Nurmi, Onatsu-Arvilommi, \& Pulkkinen, 1999). Furthermore, several studies reported correlations between maternal depression and an indulgent or uninvolved feeding style (Bronte-Tinkew, Zaslow, Capps, Horowitz, \& McNamara, 2007; Hurley et al., 2008; Topham et al., 2010). Taken together, the extant literature suggests there may be a relationship among a more external locus of control orientation, maternal depression and an indulgent or uninvolved feeding style.

Additional support for the influential role of maternal depression comes from the only existing study examining locus of control and feeding style (Ystrom, Barker \& Vollrath, 2012). In this study, the authors found that a more external locus of control orientation mediates the relationship between negative affect and behaviors associated with an authoritarian feeding style (i.e., pressure to eat and food restriction). These findings demonstrate support for a relationship among a more external locus of control, feeding style and maternal depression. The negative affect construct, however, combines a variety of psychological facets, such as levels of stress, anger, self-esteem, anxiety and depression, obscuring the specific interactive effects among parental locus of control, depression, and feeding style. This suggests a need for further inquiry. 


\section{Purpose of the Present Study}

Although there has been extensive research linking parental feeding style to child weight and food consumption behaviors (e.g. Faith et al., 2004; Moens et al., 2007; Patrick et al., 2005), and research connecting parental feeding style to maternal correlates, such as ethnicity (Hughes et al., 2008; Hughes et al., 2006), socioeconomic status (Blissett \& Haycraft, 2008; Francis, Hofer, \& Birch, 2001), and maternal psychopathology (Blissett \& Haycraft, 2008; Francis et al., 2001; Hughes et al., 2008), there has been limited research examining locus of control orientation and parental feeding style. Given that locus of control orientation has been associated with parenting style (Hagekull et al., 2001; Janssens, 1994; Stevens, 1988), and parenting style and parental feeding style are significantly correlated (Hubbs-Tait, Kennedy, Page, Topham, \& Harrist, 2008), it was theorized that locus of control orientation would be associated with parental feeding style.

Based on the current research it was expected that locus of control would account for variation within parental feeding style. It was predicted that a more internal locus of control would be associated with an authoritative feeding style and a more external locus of control would be associated with authoritarian or permissive (including both indulgent and uninvolved) feeding style. Additionally, maternal depression was expected to moderate the relationship between a more external locus of control orientation and a permissive feeding style.

In summary, the purpose of the present study was to:

1. Examine the relationship between locus of control orientation and parental feeding style. It was hypothesized that a more internal locus of control 
orientation would be associated with an authoritative feeding style, while a more external locus of control orientation would be associated with authoritarian and permissive feeding styles.

2. Explore whether depression changed the nature of the relationship between locus of control and parental feeding style. It was hypothesized that a more external locus of control orientation would be associated with an authoritarian feeding style when levels of depression were lower, and a permissive feeding style when levels of depression were higher.

Furthermore, it was hypothesized that an internal locus of control would be associated with an authoritative feeding style; depression was not expected to change the nature of this relationship. 


\section{Chapter II: Methods}

\section{Participants}

The current study, a secondary data analysis, used data collected from two previous studies. Participants were 68-English speaking mothers of preschool-aged children (3 to 5), who participated in both studies. As a group, participants were relatively low-income, with $60 \%$ of mothers reporting monthly incomes below the federal poverty level for a household of three (\$1,526/month), and ethnically diverse, 54.9\% Hispanic, 23.2\% African American, 12.8\% White, and 8.5\% other.

\section{Procedures}

The study examined data collected from a primary NIH -funded study (McCurdy, Gorman, Kisler \& Metallinos-Katsaras, 2012) that investigated maternal depression, food security, feeding behavior and child outcomes; and a second study

(Favasuli, 2012), which used a subsample of the primary study, and examined locus of control, decision making style and economic stress. The primary study (McCurdy et al., 2012) recruited a convenience sample of 164 mothers and their preschool aged children from seven daycare centers and a Supplemental Nutrition Assistance Program (SNAP) outreach project between October 2009 and December 2010. The daycare centers serve an ethnically diverse, typically low income population, in two urban Rhode Island communities.

Participants were recruited via flyers (in English and Spanish) distributed at each daycare center; research staff then visited the centers and the SNAP outreach project. Participants who agreed were paid \$20. After explaining the study and obtaining informed consent, trained bilingual staff orally administered the self-report 
measures to mothers, using English or Spanish versions as appropriate. Interviews lasted between 30-40 minutes. Procedures were approved by the Institutional Review Board at the University of Rhode Island.

The second study, designed as part of a graduate student master's thesis (Favasuli, 2012) included 68 participants. Data were collected between October 2009 and May 2011. Two forms of recruitment were used: mothers who were recruited for the primary study were asked to participate after they completed their interviews, and mothers who had already completed the original study were reapproached and asked to participate in the second study. Participants who agreed to be part of the subsample received \$20. The interview lasted between 10-15 minutes. Procedures were approved by the Institutional Review Board at the University of Rhode Island.

Due to the archival nature of the data and the IRB approval of the two previous studies, the Compliance Office at the University of Rhode Island waived further IRB approval of this study. De-identified data were imported into SPSS 21.0 for all statistical analyses.

\section{Measures}

Measures of parental feeding style, maternal depression and locus of control, as well as basic demographic data were drawn from larger interview batteries administered as part of the previous studies.

Parental feeding style. Parental feeding style was measured by adapting the Family Food Behavior Survey (FFBS), a 20-item questionnaire designed to assess the ways adults monitor and participate in the child's food consumption behaviors at home (McCurdy \& Gorman, 2010). The FFBS is comprised of four scales each 
demonstrating acceptable internal reliability: 1) maternal control of child eating behavior, i.e., I decide how many snacks child has, $(\alpha=.83)$; 2) maternal presence during eating, i.e., I sit down with child when s/he eats, $(\alpha=.76)$; 3$)$ child choice, i.e., my child chooses food from what is served, $(\alpha=.79)$; and, 4) organization of eating environment, my child and I watch TV while eating meal, $(\alpha=.73)$. For each item, respondents were asked to rate statements, based on how strongly they agreed, using a 5-point Likert scale ranging from 0 (never true) to 4 (always true) (McCurdy \& Gorman, 2010). The FFBS questionnaire was included Appendix A.

For the purposes of this study, the items on the FFBS survey were recoded along dimensions typically associated with parental feeding style: authoritarian, authoritative, and permissive (including both indulgent and uninvolved). Analyses of the items, using five coders reaching 100\% inter-rater agreement, yielded 3 scales authoritarian (4-items) (e.g., I decide when it is time for my child to have a snack), authoritative (5-items) (e.g., my child chooses foods from what is served), and permissive feeding styles (6-items) (e.g., I allow my child to eat snacks whenever s/he wants). Five of the original items from the FFBS were excluded from the measure, as they did not meet criteria specific to any feeding style. The recoded measure is included in Appendix B.

For each of the 15 items, statements were scored based on how strongly respondents agreed on a 5-point scale ranging from 0 (never true) to 4 (always true). Items were summed for each feeding style and divided by the total number of items in the category (e.g., authoritarian feeding style items were summed and divided by 4). This resulted in three feeding styles (authoritarian, authoritative and 
permissive) with scores ranging from 0 to 4 . Reliability coefficients were calculated and resulted in adequate Cronbach's alpha scores $\alpha=.73$ (authoritarian), $\alpha=.61$ (authoritative), $\alpha=.57$ (permissive).

Locus of control. Locus of control was measured using an abbreviated version of Rotter's (1966) Locus of Control Scale (Gurin, Gurin, \& Morrison, 1978). The questionnaire is comprised of 13 -items; each item contains two statements reflecting an internal and an external belief. For example, one item includes the following two statements: 1) "When I make plans, I am almost certain that I can make them work" (Internal), or 2) "It is not always wise to plan too far ahead because many things turn out to be a matter of good fortune anyhow" (External). After each pair of statements was read, participants were asked to choose the statement that more accurately reflected their own beliefs. Responses were coded 0 for external and 1 for internal. The 13 -item responses were summed, for a total score ranging form $0-13$, with lower scores indicating a more external locus of control orientation and higher scores indicating a more internal locus of control orientation. This measure has been previously used and validated (Greenberger et al., 1989; Howell \& Avolio, 1993), having a demonstrated reliability $(\alpha=.69)$ and a satisfactory discriminant validity (Gurin, Gurin, \& Morrison, 1979). The full measure is included in Appendix C.

Maternal depression. Maternal depression was measured using the Center for Epidemiologic Studies Depression Scale (CES-D; Radloff, 1991), a 20-item self-report instrument that screens for the presence of depressive symptoms during the previous week. Participants were asked to respond to 20 statements, such as "I 
felt everything I did was an effort," using a 4-point rating scale ranging from 0 (rarely) to 3 (most/all of the time). Total scores on the CES-D can range from 0 to 60 , with higher scores indicating greater levels of depressive symptomology. A score of 16 or higher is a clinical indicator of depression (Radloff, 1977). The measure has achieved high internal consistency for both English $(\alpha>.84)$ and Spanish $(\alpha=.90)$ versions (Gonzalez et al., 1995; Hann et al., 1999; Radloff, 1977). The full measure is included in Appendix D.

\section{Covariates}

Participants' characteristics were drawn from a larger interview battery, which assessed demographic and maternal health. Maternal variables included marital/partner status, age, years of schooling, and ethnicity/race. Data on monthly income as well as participation in a range of government assistance programs was also collected. Food security status during the previous 12 months was measured with the USDA 18-item Food Security Core Module and classified as follows: Household food secure $=\leq 2$ affirmative responses, household food insecure without hunger $=3$ to 7 affirmative responses, household food insecure with hunger $=\geq 8$ affirmative responses. ${ }^{1}$

1 The USDA currently defines household food security as high food security, marginal food security, low food security and very low food security. The food security categories used in this study reflect the terms in place when the data were collected to provide continuity across studies using these data. 


\section{Analyses}

Data were analyzed using SPSS 21.0. Measures of central tendency (mean, median, mode), variance, skewness and kurtosis were assessed for each independent and dependent variable. Skewness and kurtosis were found to be at acceptable levels (<2.0 and 4.0 respectively) across all variables (Harlow, 2005). No data were transformed or adjusted.

Descriptive statistics were examined to identify associations among sociodemographic variables and the independent and dependent variables. Correlations were assessed for significance between each demographic variable and each independent and dependent variable.

Intercorrelations were run among parental feeding styles in an effort to assess the strength of the relationships among feeding style variables.

Locus of control, depression and each parental feeding style were correlated with each other to examine the relationships between each of the variables. Maternal depression was examined as both a continuous variable and as a dichotomous variable with scores of 16 or more coded as 1 (high depression scores) and scores below 16 coded as 0 (low depression scores).

The associations among parental feeding styles and locus of control were tested (hypothesis 1) using hierarchical linear regression. Each parental feeding style was regressed using a two-step model: demographic variables were entered first, and locus of control was entered second.

Hierarchical linear regression was also used to test the second hypothesis, which examined the relationship among two parental feeding styles, authoritarian 
and permissive (dependent variables), and locus of control, depression and an interaction variable ( $Z$ score of locus of control $x \mathrm{Z}$ score of maternal depression) (predictor variables). Authoritarian and permissive feeding styles were entered in two separate four-step models to test the hypothesis with each parental feeding style independently. Demographic variables were entered first, locus of control second, and depression and the interaction variable entered third and fourth respectively. The significance level was set at $p<.05$. 


\section{Chapter III: Results}

\section{Descriptive Statistics}

Key demographic characteristics are presented in Table 1. The sample was ethnically and racially diverse, with $42.6 \%$ of mothers surveyed identifying as Hispanic/Latino and 29.4\% identifying as Black. Overall participants tended to be single (69.1\%) and working (80.9\%). Despite relatively high rates of employment, mothers were generally low-income, with $79.4 \%$ of reported incomes at or below \$2000 per month. Almost all mothers (95.6\%) participated in at least one government assistance program, and nearly three-quarters $(73.5 \%)$ participated in three or more government assistance programs. Food insecurity was relatively high among participants, with $36.8 \%$ of households reporting have experienced food insecurity within the previous 12 months.

Education levels varied widely among respondents, ranging from $8^{\text {th }}$ grade to graduate training. As a group, however, education levels tended to be low. On average mothers completed 12.7 years of school, and nearly one-quarter $(23.5 \%)$ did not graduate from high school. 
Table 1: Participant characteristics

\begin{tabular}{|c|c|c|c|}
\hline Variable & Mean (SD) & n & $\%$ \\
\hline Full Sample & & 68 & \\
\hline Age in Years & $29.90(7.32)$ & & \\
\hline \multicolumn{4}{|l|}{ Race } \\
\hline White & & 10 & $14.7 \%$ \\
\hline Black & & 20 & $29.4 \%$ \\
\hline Other $^{\mathrm{a}}$ & & 13 & $19.1 \%$ \\
\hline No answer ${ }^{\mathrm{b}}$ & & 25 & $36.8 \%$ \\
\hline \multicolumn{4}{|l|}{ Hispanic/Latino } \\
\hline Hispanic or Latino & & 29 & $42.6 \%$ \\
\hline Non-Hispanic/Non-Latino & & 39 & $57.4 \%$ \\
\hline Education & $12.72(2.5)$ & & \\
\hline $11^{\text {th }}$ grade or below & & 16 & $23.5 \%$ \\
\hline High school diploma/GED & & 24 & $35.3 \%$ \\
\hline Some post secondary & & 24 & $35.3 \%$ \\
\hline Bachelor's degree or beyond & & 4 & $5.9 \%$ \\
\hline \multicolumn{4}{|l|}{ Partner Status } \\
\hline Married/Live with partner & & 21 & $30.9 \%$ \\
\hline Single & & 47 & $69.1 \%$ \\
\hline \multicolumn{4}{|l|}{ Assistance Programs Used } \\
\hline WIC & & 41 & $60.3 \%$ \\
\hline Head Start & & 16 & $23.5 \%$ \\
\hline Heating Assistance & & 26 & $38.2 \%$ \\
\hline SSI & & 8 & $11.8 \%$ \\
\hline Rite Care & & 52 & $76.5 \%$ \\
\hline RI works/FIP & & 21 & $30.9 \%$ \\
\hline SNAP & & 44 & $64.7 \%$ \\
\hline Day Care/Child Care Assistance & & 41 & $60.3 \%$ \\
\hline Other & & 4 & $5.9 \%$ \\
\hline No programs used & & 3 & $4.4 \%$ \\
\hline Use of Multiple Assistance Programs & $3.72(1.83)$ & & \\
\hline \multicolumn{4}{|l|}{ Monthly Income Range } \\
\hline Less than or equal to $\$ 1000$ & & 22 & $32.4 \%$ \\
\hline$\$ 1001-2000$ & & 32 & $47.1 \%$ \\
\hline$\$ 2,001-3000$ & & 7 & $10.3 \%$ \\
\hline Over $\$ 3,001$ & & 7 & $10.3 \%$ \\
\hline \multicolumn{4}{|l|}{ Food Security Status } \\
\hline Food Secure & & 43 & $63.2 \%$ \\
\hline Food Insecure & & 25 & $36.8 \%$ \\
\hline
\end{tabular}

${ }^{a}$ Includes biracial (3), American Indian or Alaskan native(3), Asian (2), and unspecified (5)

${ }^{b}$ No answer was given in cases where respondents claimed Hispanic only and added no specifications. 
Descriptive data for parental feeding style, locus of control and depression is presented in Table 2. Overall, respondents more strongly endorsed authoritarian, $(\mathrm{M}=2.78, \mathrm{SD}=0.97)$, and authoritative feeding style items $(\mathrm{M}=2.91, \mathrm{SD}=0.69)$, than permissive feeding style items $(\mathrm{M}=1.55, \mathrm{SD}=0.90)$. Locus of control scores varied among respondents, measures of central tendency $(\mathrm{M}=6.5, \mathrm{SD}=1.7)$ suggest that both the external and internal ends of the continuum are represented in the sample. Scores on the depression index (CES-D) were varied as well $(\mathrm{M}=12.3$ ( $\mathrm{SD}=9.2$ ), with one-quarter of participants reporting high levels of depressive symptoms (CESD $\geq 16)$ within the previous week.

Table 2. Descriptive statistics: Parental feeding styles, locus of control and depression

\begin{tabular}{lccllc}
\hline & & & \multicolumn{2}{c}{ Range } \\
\cline { 5 - 6 } & $\mathrm{M}$ & $\mathrm{SD}$ & & Potential & Min/Max \\
\hline Authoritarian Feeding Style & 2.78 & 0.97 & $0-4$ & $0.0-4.0$ \\
Authoritative Feeding Style & 2.91 & 0.69 & $0-4$ & $1.2-4.0$ \\
Permissive Feeding Style & 1.55 & 0.90 & $0-4$ & $0.0-3.4$ \\
Locus of Control & 6.52 & 1.73 & $0-13$ & $2.0-10.0$ \\
Depression & 12.25 & 9.22 & $0-60$ & $0.0-41.0$ \\
\hline
\end{tabular}

Pearson product-moment correlations revealed strong associations among feeding style variables. Higher scores on authoritarian feeding style were correlated with higher scores on authoritative feeding style $(r(66)=0.47 \mathrm{p}<.001)$. Additionally, higher scores on authoritarian feeding style $(r(66)=-0.48, \mathrm{p}<.001)$ and higher scores on authoritative feeding style $(r(66)=-0.28, \mathrm{p}<.05)$ were associated with lower scores on permissive feeding style. Taken together, the data suggest that mothers who strongly endorse authoritarian or authoritative feeding 
styles are less likely to endorse permissive feeding style.

\section{Covariate Analyses}

Associations between the independent and dependent variables and continuous demographic variables yielded few significant findings (Table 3).

Results indicate that the use of government assistance programs was associated with depression $(r(66)=0.30, \mathrm{p}<.05)$, with mothers reporting participation in more programs having higher levels of depressive symptomatology. Age, education, income were not associated with the independent or dependent variables.

Table 3. Pearson product-moment correlations: Parental feeding style, locus of control, depression and demographic variables.

\begin{tabular}{lcccc}
\hline & Age & $\begin{array}{c}\text { Gov't } \\
\text { Assistance }\end{array}$ & Education & $\begin{array}{c}\text { Income } \\
\text { Range }\end{array}$ \\
\hline Authoritarian & 0.06 & -0.21 & 0.19 & 0.03 \\
Authoritative & 0.03 & -0.20 & 0.14 & 0.06 \\
Permissive & -0.04 & 0.21 & -0.06 & -0.16 \\
Locus of Control & -0.14 & 0.05 & -0.02 & 0.17 \\
Depression & -0.22 & $0.30 *$ & -0.11 & -0.20 \\
\hline
\end{tabular}

Note: $\mathrm{N}=68$, Significant correlation, ${ }^{*} p<.05$

Examination of the relationships between the independent and dependent variables and the categorical demographic variables partner status, food security and ethnicity, were explored using ANOVA. Partner status was significantly associated with depression $(F(1,66)=8.74, \mathrm{p}<.01)$ and permissive feeding style $(F(1,66)=6.25 \mathrm{p}<.05)$. Mothers who were single were more likely to experience depressive symptoms and endorse permissive feeding style, as compared to mothers who were partnered. Additionally, food security was associated with locus 
of control, $(F(1,66)=6.81, \mathrm{p}<.05)$, with mothers who reported their households as food secure, more likely to endorse an internal locus of control, as compared to mothers who reported food insecure households. There were no significant associations between race or ethnicity and locus of control, feeding style, or depression.

\section{Locus of Control, Parental Feeding Styles and Maternal Depression}

Correlations between locus of control, parental feeding style and maternal depression are reported in Table 4. Contrary to expectations, locus of control was not significantly correlated to authoritarian or authoritative feeding style, and was significantly (positively) correlated with permissive feeding style $(r(66)=0.26 \mathrm{p}<.05)$ Accordingly, mothers with a more internal locus of control were more likely to endorse a permissive feeding style. Maternal Depression was not significantly related to any parental feeding style but was positively correlated with locus of control $(r$ $(66)=-0.26, \mathrm{p}<.05)$, a more internal locus of control was associated with lower levels of depressive symptomatology.

Table 4. Pearson product-moment correlations: Parental feeding styles, locus of control, and depression

\begin{tabular}{lcccc}
\hline Measure & \multicolumn{3}{c}{ Pearson Correlation Coefficient } \\
\hline & Authoritarian & Authoritative & Permissive & Locus of Control \\
\hline Authoritative & $0.47^{* *}$ & & & \\
Permissive & $-0.48^{* *}$ & $-0.28^{*}$ & & \\
Locus of Control & 0.00 & 0.08 & $0.26^{*}$ & $-0.26^{*}$ \\
Depression & 0.05 & 0.01 & 0.09 & \\
\hline
\end{tabular}

$* \mathrm{p}<0.05$ (2-tailed)

$* * \mathrm{p}<0.01$ level (2-tailed) 
To further test the hypotheses hierarchical linear regression was used, with each parental feeding style regressed on locus of control, controlling for demographic variables.) (hypothesis 1). Results of the regression analyses for permissive, authoritarian, and authoritative feeding styles are presented in Tables 5, 6, and 7, respectively. In Step 1, none of the models reached statistical significance, indicating that the demographic variables were not significant predictors of feeding style. Similar to the correlational findings, locus of control met significance criterion only as a predictor for permissive feeding style. $\left(R^{2}=.25, F(8,59)=2.47, \mathrm{p}<.05\right)$. As shown in Step 2, the beta coefficient ( $\beta=0.39$ ) indicates that a more internal locus of control corresponded to a permissive feeding style. Notably, when locus of control was entered as a predictor, food security status also became significant, with permissive feeding style mothers more likely to be food insecure (Table 5). Locus of control did not reach significance criterion as a predictor for either authoritarian (Table 6) or authoritative (Table 7) feeding styles.

As indicated by hypothesis 2, maternal depression (Step 3) and an interaction variable (ZLOC * ZDep) (Step 4) were then added as predictors for permissive and authoritarian feeding style models, in order to assess the interactive effects of locus of control and maternal depression on permissive and authoritarian feeding styles. The model for permissive feeding style remained significant with the addition of maternal depression (Step 3) $\left(R^{2}=.27, F(9,58)=2.41, \mathrm{p}<.05\right)$ and the interaction term (Step 4) $\left(R^{2}=.28, F(10,57)=2.24, \mathrm{p}<.05\right)$, though neither variable entered significantly. Partner status became significant with the addition of maternal depression as a predictor variable and remained significant with the addition of the interaction term, suggesting 
that after controlling for depressive symptomotology, mothers without partners were more likely to use a permissive feeding style than those who were partnered. The addition of maternal depression and the interactive term did not contribute significantly to the overall prediction of authoritarian feeding style. 


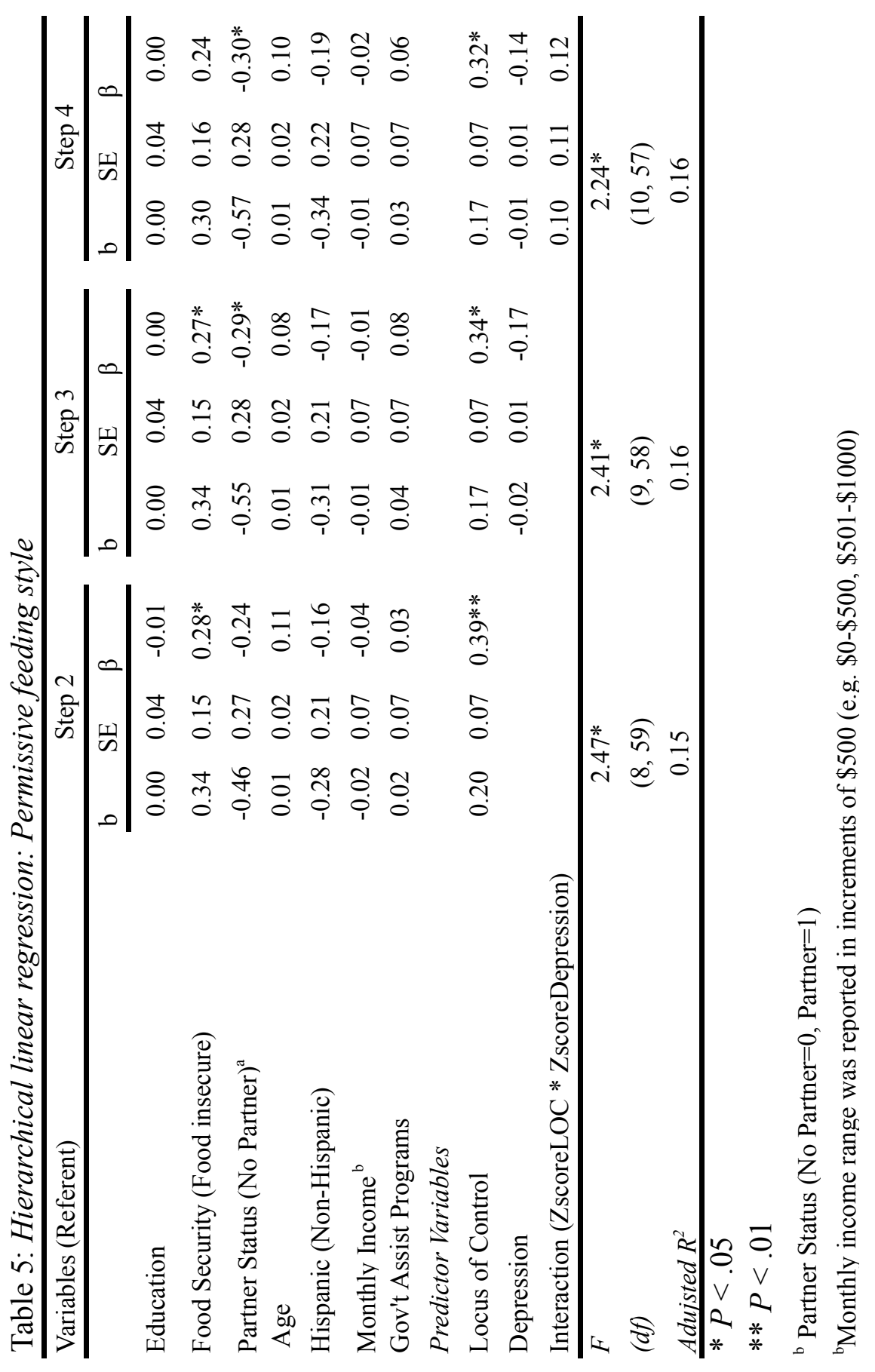




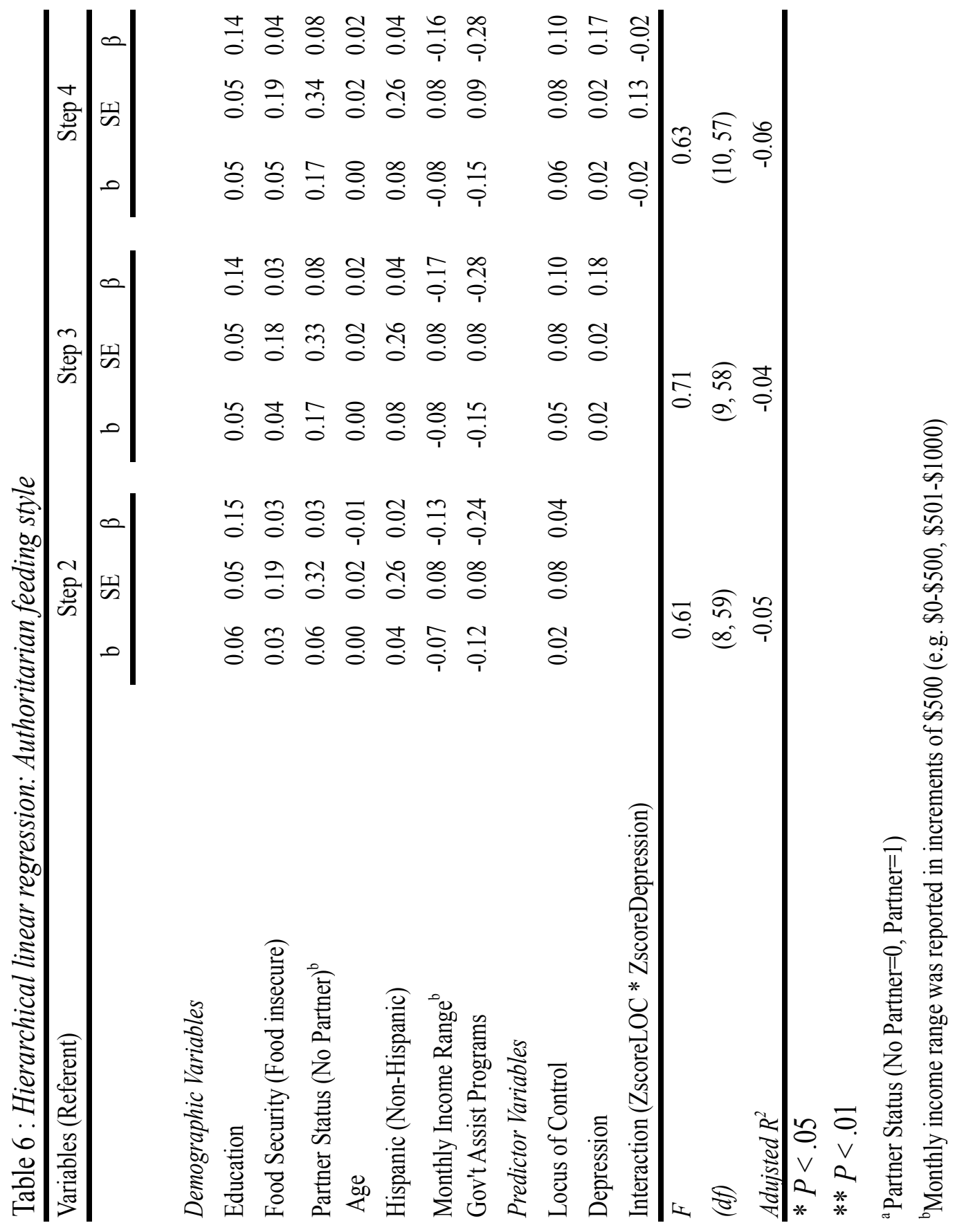


Table 7: Hierarchical linear regression: Authoritative feeding style

\begin{tabular}{|c|c|c|c|}
\hline \multirow[t]{2}{*}{ Variables (Referent) } & \multicolumn{3}{|c|}{ Step 2} \\
\hline & $\mathrm{b}$ & SE & $\beta$ \\
\hline \multicolumn{4}{|l|}{ Demographic Variables } \\
\hline Education & 0.03 & 0.04 & 0.12 \\
\hline Food Security (Food insecure) & 0.14 & 0.13 & 0.15 \\
\hline Partner Status (No Partner) ${ }^{\mathrm{a}}$ & 0.14 & 0.22 & 0.10 \\
\hline Age & 0.00 & 0.01 & -0.04 \\
\hline Hispanic (Non-Hispanic) & -0.31 & 0.18 & -0.22 \\
\hline Monthly Income ${ }^{b}$ & -0.02 & 0.06 & -0.05 \\
\hline Gov't Assist Programs & -0.08 & 0.06 & -0.20 \\
\hline \multicolumn{4}{|l|}{ Predictor Variables } \\
\hline Locus of Control & 0.01 & 0.06 & 0.02 \\
\hline$F$ & \multicolumn{2}{|c|}{1.01} & \\
\hline$(d f)$ & \multicolumn{2}{|c|}{$(8,59)$} & \\
\hline Adujsted $R^{2}$ & \multicolumn{2}{|c|}{0} & \\
\hline \multicolumn{4}{|l|}{$* P<.05$} \\
\hline \multicolumn{4}{|l|}{$* * P<.01$} \\
\hline${ }^{a}$ Partner Status (No Partner $=0$, & & & \\
\hline
\end{tabular}




\section{Chapter IV: Discussion}

The purpose of this research was to explore the utility of locus of control as a predictor of parental feeding style in a low-income population. More specifically, the study sought to investigate the role of locus of control in contributing to variations in feeding style, and to determine whether depression changed the nature of the relationship between locus of control orientation and feeding style.

It was hypothesized that a more internal locus of control orientation would be associated with an authoritative feeding style, while a more external locus of control orientation would be associated with permissive and authoritarian feeding styles. Depression was expected to moderate the relationship between a more external locus of control and authoritarian and permissive feeding styles, such that an external locus of control would be associated with an authoritarian feeding style when levels of depression were lower and a permissive feeding style when levels of depression were higher. Depression was not expected to affect the relationship between locus of control and authoritative feeding style.

The results of the analyses provided little support for the proposed hypotheses. Neither authoritarian nor authoritative feeding styles were significantly associated with locus of control. Additionally, no feeding style was associated with depression.

However, in contrast to expectations, it is interesting to note that permissive feeding style was associated with a more internal locus of control. That is, mothers who more highly endorsed a permissive feeding style, in contrast to authoritative and authoritarian styles, were also more likely to demonstrate a more internal locus 
of control. The prediction that permissive feeding style would be associated with a more external locus of control was based, in part, on previous research that found associations between maternal depression and permissive feeding styles, (e.g,. Bronte-Tinkew, Zaslow, Capps, Horowitz, \& McNamara, 2007; Hurley et al., 2008; Topham et al., 2010), and maternal depression and a more external locus of control (Gerdes et al., 2007; Leung \& Slep, 2006). However, mothers in our study who endorsed items associated with a permissive feeding style were no more likely to be depressed than other mothers in our sample. Furthermore, an examination of the responses to the feeding style scales show that mothers who most highly endorsed the permissive style were still not endorsing the items very strongly. For example, permissive feeding style scores had the lowest mean score $(\mathrm{M}=1.55$, $\mathrm{SD}=.90)$ and the narrowest range $(0.00--3.40)$, when compared to authoritarian and authoritative feeding styles, suggesting that even mothers who endorsed items associated with permissive feeding style were more often responding "sometimes" rather than "always." It is well known that most parents engage in a wide variety of parenting behaviors including authoritative, permissive, and authoritarian, depending on the circumstances. While far from definitive, it may well be that parents who feel more control over their ability to parent (internal locus of control orientation) were actually more willing to moderately endorse behaviors perceived as permissive.

Our results, though unexpected, find limited support in the literature. While a search found no studies that directly linked permissive feeding style to a more internal locus of control, there may be support for an association. Research 
examining the relationship between locus of control and positive affect has found positive associations between a more internal locus of control and positive affect in facilitating feelings of well-being (DeNeve \& Cooper 1998; Klonowicz, 2001). Building on these findings is research exploring the relationship between positive parental affect and feeding style. Hughes and colleagues (2008) found an association between positive affect and indulgent feeding style in two low-income communities. Though far from definitive, this literature could be interpreted to support an association between a more internal locus of control and permissive feeding style among this sample of low-income mothers of young children. It may be that the observed association between permissive feeding style and a more internal locus of control is moderated by some aspects of positive affect. Unfortunately, our data do not allow us to test for these associations. Future research should attempt to examine more nuanced ways in which feeding styles interact with other variables including personal attributes of parents and their children.

It is notable that data were collected in low-income urban communities in Rhode Island between October 2009 and May 2011, in the midst of an economic crisis. The poverty rate in Rhode Island was above 12\% between 2007 and 2011 (U.S Census Bureau, 2013) and the unemployment rate hovered above $11 \%$ for much of that time (Bureau of Labor Statistics, 2013). It is widely known that women and children are disproportionately affected by rising poverty rates making it likely then that our respondents were negatively impacted by the state recession. Thus, our findings are best examined within the context of this economic crisis, as 
it can be expected that the vast majority of participant households were experiencing economic stress that may have masked more subtle nuances about parental feeding style.

\section{Limitations}

This study faced a variety of limitations. Most notably, the parental feeding style categories were created using the Family Food Behavior Survey (McCurdy \& Gorman, 2010), which was not designed to assess parental feeding style. The FFBS was developed to assess the ways adults monitor and participate in the child's food consumption behaviors at home. While the FFBS addresses many of the same issues explored in parental feeding style literature and measures, it is does not assess parental feeding style explicitly. Though the categories used for this study approximated the feeding style categories on the Caregiver's Feeding Styles Questionnaire (CFSQ) (Hughes et al., 2005), they did not capture the categories entirely. For example, permissive feeding style could not be parsed into indulgent and uninvolved feeding styles, as it is in studies that use the CFSQ.

An additional limitation of our study was the locus of control measure. Rotter (1966) designed the scale as a generalizable tool with predictive value to provide information about expected behaviors based on intraindividual characteristics that remained relatively constant across time and place. Later research, however, suggested that locus of control was related both to intraindividual characteristics and situation specific criteria (Lefcourt, 1976). To that end criterion-specific scales have been developed to measure health locus of control (Watson et al., 1978) and parental locus of control (Campsi et al., 1986). 
The development of criterion-specific locus of control scales suggests that locus of control is affected by a variety of factors (e.g. situation, individual characteristics) and may adjust according to situation. Thus, it is possible that the locus of control measure (Gurin, et al., 1978) lacked precision and did not capture qualities of locus of control orientation specific to parenting and maternal feeding style.

Finally, the study may have been limited by the modest sample size, which reduced statistical power. This may have played a role in limiting the significance of some of the statistical analyses conducted. For example, we found an almost significant relationship between income and permissive feeding style, that is mothers who were endorsed permissive feeding style tended to be lower income, however, findings did not reach significance.

\section{Future Directions and Conclusions}

This study posed an important question about the way intraindividual characteristics, specifically locus of control orientation, affect parental feeding style. Though major hypotheses were not supported in the analyses, the significant association between permissive feeding style and a more internal locus of control bears further exploration.

The literature around both feeding style and locus of control has generated a variety of hypotheses, independent of each other, to explain the psychosocial underpinnings of behavior. Race, ethnicity and culture are a constellation of factors that feature prominently in both areas. For example, researchers have found that African American and Hispanic/Latino mothers tend to be either permissive or authoritarian in their approach to child feeding than mothers of other racial/ethnic 
groups (Hughes, et al., 2008; Ventura, Gromis, \& Lohse, 2010). Additionally, African American and Hispanic/Latino mothers are more likely, than their white counterparts, to articulate a desire for heavier children, resulting in a more permissive/indulgent approach to feeding (Murashima, Hoerr, Hughes \& Kaplowitz, 2012; Rosas, et al., 2010; Skelton, Busey Havens, 2006). Similarly, the locus of control literature suggests that cultural variations may also affect locus of control orientation. For example a recent meta-analysis identified cultural variations related to locus of control orientation and anxiety and depressive symptomatology in individuals from collectivist and individualistic countries. More specifically, researchers found a strong relationship existed between an external locus of control and anxiety in individuals from individualistic countries, but not in individuals from collectivist countries (Cheung, Chio and Chan (2013). This research may in part explain the association we found between a permissive feeding style and a more internal locus of control. While we found no racial or ethnic differences among our sample, perhaps due in part to a small sample size, it is an area of research that warrants further exploration as race/ethnicity likely influences both locus of control and parental feeding style.

In addition to race, ethnicity and culture, literature specific to feeding style suggests that characteristics of the child and family environment likely influence maternal feeding style. For example, several studies have found child weight to be a predictor of feeding style, theorizing that mothers who view their children as underweight are more likely to be permissive in their approach to child feeding, while mothers who view their children as overweight are more likely to be authoritarian in their approach (e.g. Hurley et al., 2008). Another theory proffered by Hughes and 
colleagues (2011) indicates that mothers engage in indulgent feeding style as way to maintain a pleasant emotional climate during mealtimes. As a result, they make few demands on their children in regards to the quality and quantity of foods they eat. These theories suggest that parental feeding style is affected by a variety of factors related to the transactional nature of parent child relationships.

Thus based on our findings and the extant literature, future research should explore the bidirectional nature of the parent-child relationship and its effects on locus of control and feeding style. Furthermore, ethnicity and culture feature prominently in both the feeding style and locus of control literature; researchers would benefit from exploring the interaction effects of culture and ethnicity relative to locus of control and parental feeding style. 


\section{Appendix A}

Scale developed by McCurdy \& Gorman, 2010.

\section{Family Food Behavior Study - Part B Typical Family Food Behaviors}

READ TO PARTICIPANT: We are interested in learning about how food choices are typically made in your house and how you and your child make decisions about what, when and where to eat. In answering these questions, I want you to think about [name of child]. I will read you a number of statements and ask you to decide whether this statement is: Never true, Rarely true, Sometimes true, Often true or Always true. Some of these statements may sound similar.

\section{;HOW YELLOW RESPONSE CARD \#1)}

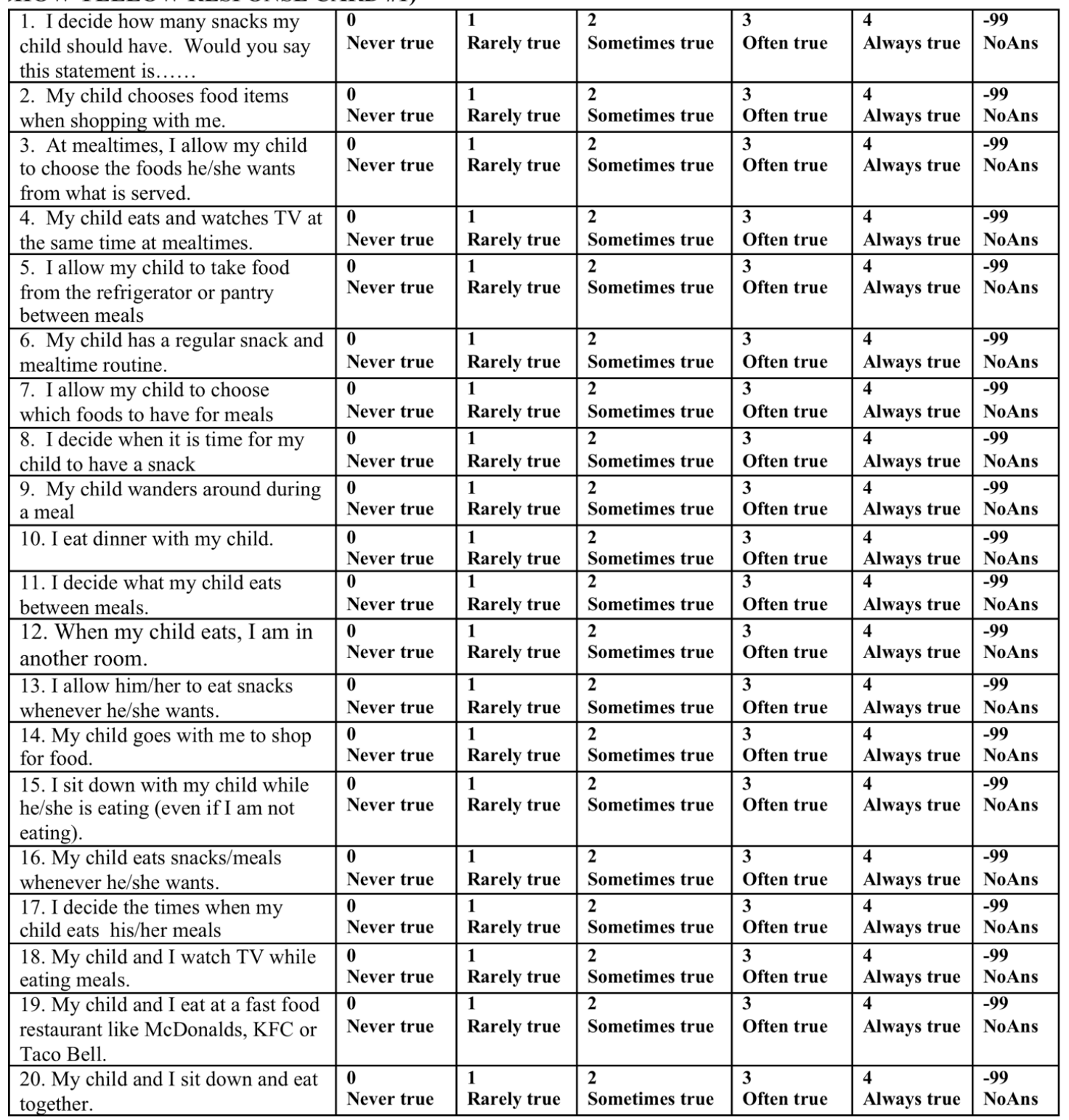




\section{Appendix B}

Feeding Style

1 I decide how many snacks child has

Authoritarian

2 Child chooses food items while shopping

N/A

3 Child chooses foods from what is served

Authoritative

4 Child eats and watches TV at mealtimes

N/A

5 I allow child to take food between meals

Permissive

6 Child has regular snack and mealtime routine

Authoritative

7 Child chooses which food to have for meals

Permissive

8 I decide my child's snack time

9 My child wanders during meals

Authoritarian

10 I eat dinner with child

Permissive

11 I decide what child eats between meals

Authoritative

12 When child eats I am in another room

Authoritarian

13 I allow child to eat snacks whenever s/he wants

Permissive

14 Child shops for food with me

Permissive

15 I sit down with child when s/he eats

$\mathrm{N} / \mathrm{A}$

16 My child eats snacks/meals whenever s/he wants

Authoritative

Permissive

17 I decide the time when my child eats meals

Authoritarian

18 My child and I watch TV while eating meals

N/A

19 My child and I eat at fast food restaurants

$\mathrm{N} / \mathrm{A}$

20 My child and I sit and eat together

Authoritative 


\section{Appendix C}

Abbreviated version of Rotter's Locus of Control Scale developed by Gurin, Gurin \& Morrison, 1978.

1) A. Becoming a success is a matter of hard work; luck has little or nothing to do with it.

B. Getting a good job depends mainly on being in the right place at the right time.

2) A. Who gets to be the boss often depends on who was lucky enough to be in the right place first.

B. Who gets to be the boss depends on who has the skill and ability; luck has little or nothing to do with it.

3) A. I have often found that what is going to happen will happen.

B. Trusting to fate has never turned out as well for me as making a decision to take a definite course of action.

4) A. When I make plans, I am almost certain that I can make them work.

B. It is not always wise to plan too far ahead because many things turn out to be a matter of good or bad fortune anyhow.

5) A. In my case, getting what I want has little or nothing to do with luck.

B. Many times we might just as well decide what to do by flipping a coin.

6) A. Many times I feel that I have little influence over the things that happen to me.

B. It is impossible for me to believe that chance or luck play an important role in my life.

7) A. What happens to me is my own doing.

B. Sometimes I feel that I don't have enough control over the direction my life is taking.

8) A. No matter how hard you try, some people just don't like you.

B. People who can't get others to like them don't understand how to get along with others.

9) A. It is hard to know whether or not a person really likes you.

B. How many friends you have depends upon how nice a person you are.

10) A. People are lonely because they don't try to be friendly.

B. There's not much use in trying too hard to please people; if they like you 
they like you.

11) A. In the long run, people get the respect they deserve in this world. B. Unfortunately, an individual's worth often passes unrecognized no matter how hard he tries.

12) A. One of the major reasons why we have wars is because people don't take enough interest in politics.

B. There will always be wars, no matter how hard people try to prevent them.

13) A. Leadership positions tend to go to capable people who deserve being chosen.

B. It's hard to know why some people get leadership positions and others don't. Ability doesn't seem to be important factor. 


\section{Appendix D}

The CES-D scale (Radloff, 1977)

\section{Center for Epidemiologic Studies Depression Scale (CES-D), NIMH}

Below is a list of the ways you might have felt or behaved. Please tell me how often you have felt this way during the past week.

\begin{tabular}{|c|c|c|c|c|}
\hline & \multicolumn{4}{|c|}{ During the Past } \\
\hline & $\begin{array}{c}\text { Rarely or none of } \\
\text { the time (less than } \\
1 \text { day ) }\end{array}$ & $\begin{array}{l}\text { Some or a } \\
\text { little of the } \\
\text { time }(1-2 \\
\text { days })\end{array}$ & $\begin{array}{c}\text { Occasionally or a } \\
\text { moderate amount of time } \\
\text { (3-4 days) }\end{array}$ & $\begin{array}{l}\text { Most or all of } \\
\text { the time (5-7 } \\
\text { days) }\end{array}$ \\
\hline $\begin{array}{l}\text { 1. I was bothered by things that usually } \\
\text { don't bother me. }\end{array}$ & $\square$ & $\square$ & $\square$ & $\square^{+}$ \\
\hline 2. I did not feel like eating; my appetite & $\square$ & $\square$ & $\square$ & $\square$ \\
\hline $\begin{array}{l}\text { was poor. } \\
\text { 3. I felt that I could not shake off the } \\
\text { blues even with help from my family or } \\
\text { friends. }\end{array}$ & $\square$ & $\square$ & $\square$ & $\square$ \\
\hline $\begin{array}{l}\text { 4. I felt I was just as good as other } \\
\text { people. }\end{array}$ & $\square$ & $\square$ & $\square$ & $\square$ \\
\hline $\begin{array}{l}\text { 5. I had trouble keeping my mind on } \\
\text { what I was doing. }\end{array}$ & - & - & $\square$ & L \\
\hline 6. I felt depressed. & & & & 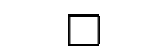 \\
\hline $\begin{array}{l}\text { 7. I felt that everything I did was an } \\
\text { effort. }\end{array}$ & & & & \\
\hline 8. I felt hopeful about the future. & 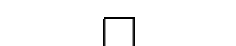 & 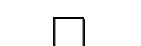 & $\square$ & 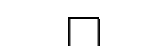 \\
\hline 9. I thought my life had been a failure. & & $\square$ & $\square$ & $\square$ \\
\hline 10. I felt fearful. & & & 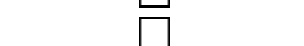 & 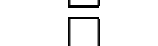 \\
\hline 11. My sleep was restless. & & 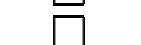 & 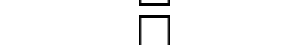 & \\
\hline 12. I was happy. & & & $\square$ & \\
\hline 13. I talked less than usual. & & 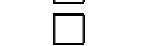 & $\square$ & 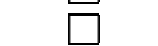 \\
\hline 14. I felt lonely. & & 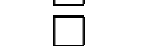 & 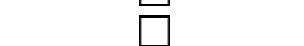 & 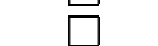 \\
\hline 15. People were unfriendly. & & 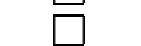 & 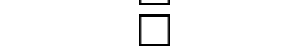 & 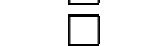 \\
\hline 16. I enjoyed life. & $\square$ & $\square$ & $\square$ & $\square$ \\
\hline 17. I had crying spells. & & 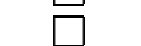 & 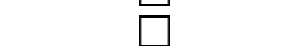 & 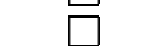 \\
\hline 18. I felt sad. & & 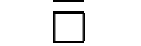 & 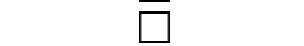 & \\
\hline 19. I felt that people dislike me. & 7 & $\square$ & $\square$ & $\square$ \\
\hline 20. I could not get "going." & & & & \\
\hline
\end{tabular}

SCORING: zero for answers in the first column, 1 for answers in the second column, 2 for answers in the third column, 3 for answers in the fourth column. The scoring of positive items is reversed. Possible range of scores is zero to 60 , with the higher scores indicating the presence of more symptomatology. 


\section{Appendix E}

\section{Statement on Diversity in Research}

This research project endeavors to include participants from a variety of cultural and ethnic backgrounds to ensure that the findings are equally beneficial to and representative of the population: low-income mothers of preschool age children. Specifically, this study will examine data that includes an ethnically diverse sample: 54.9\% Hispanic, 12.8\% white, 23.2\% African American, 8.5\%. 


\section{Bibliography}

Addy, S., \& Wight, V. R. (2012). Basic facts about Low-income children, 2010: Children under Age 18. National Center for Children in Poverty.

Aunola, K., Nurmi, J. E., Onatsu-Arvilommi, T., \& Pulkkinen, L. (1999). The role of parents' self-esteem, mastery-orientation and social background in their parenting styles. Scandinavian Journal of Psychology, 40(4), 307-17.

Baldwin, A. L., Baldwin, C., Cole, R E. (1990). Stress resistant families and stress resistant children. In Risk and Protective Factors in the Development of Psychopathology. Edited by: Rolf, J. E., Masten, A. S., Ciccheti, D. New York: Cambridge University Press: 257-280.

Banghart, P. (2012). Comprehensive obesity prevention in early childhood: Promising federal and state initiatives. National Center for Children in Poverty.

Banks, J. A. (1988). Ethnicity, class, cognitive, and motivational styles: Research and teaching implications. The Journal of Negro Education, 57(4), 452-466.

Baumrind, D. (1991). The influence of parenting style on adolescent competence and substance use. Journal of Early Adolescence, 11(1), 56-95.

Blissett, J. (2011). Relationships between parenting style, feeding style and feeding practices andfruit and vegetable consumption in early childhood. Appetite, $57(3), 826-31$.

Blissett, J., \& Haycraft, E. (2008). Are parenting style and controlling feeding practices related? Appetite, 50(2-3), 477-85.

Bronte-Tinkew, J., Zaslow, M., Capps, R., Horowitz, A., \& McNamara, M. (2007). 
Food insecurity works through depression, parenting, and infant feeding to influence overweight and health in toddlers. The Journal of Nutrition, 137(9), $2160-5$.

Bugental, D. B., Caporael, L., \& Shennum, W. A. (1980). Experimentally produced child uncontrollability: effects on the potency of adult communication patterns. Child development, 51(2), 520-8.

Bureau of Labor Statistics, U.S. Department of Labor (2013) Over-the-year change in unemployment rates for states annual average rankings 2010-2011, Retrieved on June 10, 2013 from http://www.bls.gov/lau/lastch11.htm

Bureau of Labor Statistics, U.S. Department of Labor (2011). Over-the year changes in state unemployment rates annual average rankings 2009-2010. Retrieved on June 10, 2013 from http://www.bls.gov/lau/lastch10.htm

Bronfenbrenner, U. (1979). The Ecology of Human Development: Experiments by Nature and Design. Cambridge, MA: Harvard University Press.

Campis, L., Lyman, R. D., \& Prentice-Dunn, S. (1986). Parental locus of control scale: Development and validation. Journal of Clinical Child Psychology, 15(3), 260-267.

Carnell, S., \& Wardle, J. (2007). Associations between multiple measures of parental feeding and children's adiposity in United Kingdom preschoolers. Obesity, 15(1), 137-44. doi:10.1038/oby.2007.513

Centers for Disease Control and Prevention. (2012). Obesity among low-income preschool children. Retrieved from http://www.cdc.gov/obesity/downloads/PedNSSFactSheet.pdf 
Clark, H. R., Goyder, E., Bissell, P., Blank, L., Walters, S. J., \& Peters, J. (2008). A pilot survey of socio-economic differences in child-feeding behaviours among parents of primary-school children. Public health nutrition, 11(10), 1030-6. doi:10.1017/S1368980007001401

Cohen, J. (1992). Statistical power analysis. Current directions in psychological science, 1(3), 98-101.

Coyne, L. W., \& Thompson, A. D. (2011). Maternal depression, locus of control, and emotion regulatory strategy as predictors of preschoolers' internalizing problems. Journal of Child and Family Studies, 20(6), 873-883.

Dallman MF, Pecoraro N, Akana SF, et al. (2003) hronic stress and obesity: a new view of "comfort food". Proceedings of the National Academy of Sciences, 100(20), 11696-11701.

Darling, N., \& Steinberg, L. (1993). Parenting style as context: An integrative model. Psychological Bulletin, 113(3), 487-496.

DeNeve, K. M., \& Cooper, H. (1998). The happy personality: a meta-analysis of 137 personality traits and subjective well-being. Psychological bulletin, 124(2), 197.

Faith, M. S., Scanlon, K. S., Birch, L. L., Francis, L. A., \& Sherry, B. (2004). Parent-child feeding strategies and their relationships to child eating and weight status. Obesity Research, 12(11), 1711-22.

Favasuli, S. (2012). Locus of control and decision making style as predictors of economic stress (Unpublished master's thesis). University of Rhode Island, Kingston, R.I. 
Feinberg, E., Kavanagh, P. L., Young, R. L., \& Prudent, N. (2008). Food insecurity and compensatory feeding practices among urban black families. Pediatrics, 122(4), e854-60. doi:10.1542/peds.2008-0831

Francis, L. A., Hofer, S. M., \& Birch, L. L. (2001). Predictors of maternal childfeeding style: Maternal and child characteristics. Appetite, 37(3), 231-43.

Freed, R. D., \& Tompson, M. C. (2011). Predictors of parental locus of control in mothers of pre- and early adolescents. Journal of Clinical Child and Adolescent Psychology, 40(1), 100-10.

Garner, C. W., \& Cole, E. G. (1986). The achievement of students on low-SES settings: An investigation of the relationship between locus of control and field dependence. Urban Education, 21(2), 189-206.

Gerdes, A. C., Hoza, B., Arnold, L. E., Pelham, W. E., Swanson, J. M., Wigal, T., \& Jensen, P. S. (2007). Maternal depressive symptomatology and parenting behavior: Exploration of possible mediators. Journal of Abnormal Child Psychology, 35(5), 705-14.

Gregory, J. E., Paxton, S. J., \& Brozovic, A. M. (2010). Maternal feeding practices, child eating behaviour and body mass index in preschool-aged children: A prospective analysis. International Journal of Behavioral Nutrition and Physical Activity, 7, 55.

Grolnick, W. S., \& Ryan, R. M. (1989). Parent styles associated with children's self-regulation and competence in school. Journal of Educational Psychology, 81(2), 143-154.

Greenberger, D. B., Strasser, S., Cummings, L. L., \& Dunham, R. B. (1989). The 
impact of personal control on performance and satisfaction. Organizational Behavior and Human Decision Processes, 43, 29-51.

Gurin, P., Gurin, G., \& Morrison, B. M. (1978). Personal and ideological aspects of internal and external control. Social Psychology, 41, 275-296.

Hagekull, B., Bohlin, G., \& Hammarberg, A. (2001). The role of parental perceived control in child development: A longitudinal study. International Journal of Behavioral Development, 25(5), 429-437.

Hann, D., Winter, K., \& Jacobsen, P. (1999). Measurement of depressive symptoms in cancer patients: Evaluation of the Center for Epidemiological Studies-Depression Scale (CES-D). Journal of Psychometric Research, 46, 437-443.

Harris, S. L., \& Nathan, P. E. (1973). Parents' locus of control and perception of cause of children's problems. Journal of Clinical Psychology, 29(2), 182-184.

Hoerr, S. L., Hughes, S. O., Fisher, J. O., Nicklas, T. A., Liu, Y., \& Shewchuk, R. M. (2009). Associations among parental feeding styles and children's food intake in families with limited incomes. International Journal of Behavioral Nutrition and Physical Activity, 6, 55.

Hubbs-Tait, L., Kennedy, T. S., Page, M. C., Topham, G. L., \& Harrist, A. W. (2008). Parental feeding practices predict authoritative, authoritarian, and permissive parenting styles. Journal of the American Dietetic Association, 108(7), 1154-61; discussion 1161-2.

Hughes, S. O., Shewchuck, R. M., Baskin, M. L., Nicklas, T, A., \& Qu, H. (2008). Indulgent feeding style and children's weight status in preschool. Journal of 
Developmental and Behavioral Pediatrics, 29(5), 403-410.

Hughes, Sheryl O, Anderson, C. B., Power, T. G., Micheli, N., Jaramillo, S., \& Nicklas, T. A. (2006). Measuring feeding in low-income African-American and Hispanic parents. Appetite, 46(2), 215-23.

Hughes, Sheryl O, Power, T. G., Orlet Fisher, J., Mueller, S., \& Nicklas, T. A. (2005). Revisiting a neglected construct: Parenting styles in a child-feeding context. Appetite, 44(1), 83-92.

Hurley, K. M., Black, M. M., Papas, M. a, Caulfield, L. E., \& Caufield, L. E. (2008). Maternal symptoms of stress, depression, and anxiety are related to nonresponsive feeding styles in a statewide sample of WIC participants. The Journal of Nutrition, 138(4), 799-805.

Janssens, J. (1994). Authoritarian child rearing, parental locus of control, and the child's behvaiour style. International Journal of Behavioral Development, 17, $485-501$.

Joyce, J. L., \& Zimmer-Gembeck, M. J. (2009). Parent feeding restriction and child weight. The mediating role of child disinhibited eating and the moderating role of the parenting context. Appetite, 52(3), 726-734.

Kendler, K. S., Sham, P. C., \& MacLEAN, C. J. (1997). The determinants of parenting: An epidemiological, multi-informant, retrospective study. Psychological Medicine, 27(3), 549-563.

Klonowicz, T. (2001). Discontented people: reactivity and locus of control as determinants of subjective well-being. European Journal of Personality, 15(1), 29-47. 
Kormanik, M. B., \& Rocco, T. S. (2009). Internal versus external control of reinforcement: A review of the locus of control construct. Human Resource Development Review, 8(4), 463-483.

Kröller, K., \& Warschburger, P. (2008). Associations between maternal feeding style and food intake of children with a higher risk for overweight. Appetite, 51(1), 166-72.

Lachman, M. E., \& Weaver, S. L. (1998). The sense of control as a moderator of social class differences in health and well-being. Journal of personality and social psychology, 74(3), 763.

Lamborn, S. D., Dornbusch, S. M., \& Steinberg, L. (1996). Ethnicity and community context as moderators of the relations between family decision making and adolescent adjustment. Child Development, 67(2), 283.

Lefcourt, H. M. (1976). Locus of control: Current trends in theory and research. Hillsdale, NJ: Erlbaum.

Leung, D. W., \& Slep, A. M. S. (2006). Predicting inept discipline: The role of parental depressive symptoms, anger, and attributions. Journal of Consulting and Clinical Psychology, 74(3), 524-34.

Martínez García, M. F., García Ramírez, M., \& Maya Jariego, I. (2002). Social support and locus of control as predictors of psychological well-being in Moroccan and Peruvian immigrant women in Spain. International Journal of Intercultural Relations, 26(3), 287-310.

McCurdy, K., \& Gorman, K. S. (2010). Measuring family food environments in diverse families with young children. Appetite, 54(3), 615-8. 
McCurdy, K., Gorman, K. S., Kisler, T. S., Metallinos-Katsaras, E. (2012).

Associations between the family food environment, maternal depression, and child weight among low-income preschool age children. Manuscript submitted for publication.

McGroder, S. M. (2000). Parenting among low-income, African American single mothers with preschool-age children: Patterns, predictors, and developmental correlates. Child development, 71(3), 752-71.

Mitchell, S., Brennan, L., Hayes, L., \& Miles, C. L. (2009). Maternal psychosocial predictors of controlling parental feeding styles and practices. Appetite, 53(3), 384-9.

Moens, E., Braet, C., \& Soetens, B. (2007). Observation of family functioning at mealtime: A comparison between families of children with and without overweight. Journal of Pediatric Psychology, 32(1), 52-63.

Murashima, M., Hoerr, S. L., Hughes, S. O., \& Kaplowitz, S. A. (2012). Feeding behaviors of low-income mothers: Directive control relates to a lower BMI in children, and a nondirective control relates to a healthier diet in preschoolers. American Journal of Clinical Nutrition, 95, 1031-7.

doi:10.3945/ajcn.111.024257.1

Ogden, C., \& Carroll, M. (2010). Prevalence of obesity among children and adolescents: United States, trends 1963 - 1965 through 2007 - 2008. Centers for Disease Control and Prevention.

Ogden, C., Carroll, M. D., Curtin, L. R., Lamb, M. M., \& Flegal, K. M. (2010). About childhood obesity. JAMA, 303(3), 242-249. 
Ogden, J., Reynolds, R., \& Smith, A. (2006). Expanding the concept of parental control: A role for overt and covert control in children's snacking behaviour? Appetite, 47(1), 100-6.

Olvera, N., \& Power, T. G. (2010). Brief report: parenting styles and obesity in Mexican American children: a longitudinal study. Journal of pediatric psychology, 35(3), 243-249.

Patrick, H., Nicklas, T. A., Hughes, S. O., \& Morales, M. (2005). The benefits of authoritative feeding style: Caregiver feeding styles and children's food consumption patterns. Appetite, 44(2), 243-9.

Polfuss, M. L., \& Frenn, M. (2012). Parenting and feeding behaviors associated with school-aged African American and White children. Western Journal of Nursing Research, 34(5), 677-96.

Prociuk, T. J., Breen, L. J., \& Lussier, R. J. (1976). Hopelessness, internal-external locus of control, and depression. Journal of Clinical Psychology, 32(2), 299300.

Radloff, L (1977). The CES-D scale: A self-report depression scale for research in the general population. Applied Psychological Measurement, 1, 385-401.

Rhee, K. (2008). Childhood overweight and the relationship between parent behaviors, parenting style, and family functioning. The Annals of the American Academy of Political and Social Science, 615(1), 11-37. doi:10.1177/0002716207308400

Rhee, K. E., Lumeng, J. C., Appugliese, D. P., Kaciroti, N., \& Bradley, R. H. (2006). Parenting styles and overweight status in first grade. Pediatrics, 
117(6), 2047-54.

Rosas, L. G., Harley, K. G., Guendelman, S., Fernald, L. C., Mejia, F., \& Eskenazi, B. (2010). Maternal perception of child weight among Mexicans in California and Mexico. Maternal and child health journal, 14(6), 886-894.

Rotter, J. B. (1966). Generalized expectancies for internal versus external control of reinforcement. Psychological monographs: General and applied, 80(1), 1-28.

Savage, J. S., Fisher, J. O., \& Birch, L. L. (2007). Parental Influence on Eating Behavior: Conception to adolescence. Journal of Law, Medicine and Ethics, $35(1), 22-34$.

Saxton, J., Carnell, S., Van Jaarsveld, C. H. M., \& Wardle, J. (2009). Maternal education is associated with feeding style. Journal of the American Dietetic Association, 109(5), 894-8. doi:10.1016/j.jada.2009.02.010

Sleddens, E. F. C., Gerards, S. M. P. L., Thijs, C., De Vries, N. K., \& Kremers, S. P. J. (2011). General parenting, childhood overweight and obesity-inducing behaviors: A review. International Journal of Pediatric Obesity 6, e12-27.

Spruijt-metz, D., Lindquist, C. H., Birch, L. L., Fisher, J. O., \& Goran, M. I. (2002). Relation between mothers' child-feeding practices and children's. American Journal of Clinical Nutrition, 75, 581-586.

Stevens, J. H. (1988). Social support, locus of control, and parenting in three lowincome groups of mothers: black teenagers, black adults, and white adults. Child development, 59(3), 635-42.

Strauss R.S. \& Pollack H. A. (2001). Epidemic increase in childhood overweight, 1986-1998. Journal of the American Medical Association, 286, 2845-8. 
Topham, G. L., Page, M. C., Hubbs-Tait, L., Rutledge, J. M., Kennedy, T. S., Shriver, L., \& Harrist, A. W. (2010). Maternal depression and socio-economic status moderate the parenting style/child obesity association. Public Health Nutrition, 13(8), 1237-44.

Tovar, A., Hennessy, E., Pirie, A., Must, A., Gute, D. M., Hyatt, R. R., Kamins, C. L., et al. (2012). Feeding styles and child weight status among recent immigrant mother-child dyads. The international journal of behavioral nutrition and physical activity, 9, 62. doi:10.1186/1479-5868-9-62

U.S. Census Bureau (2013). State and county QuickFacts. Retrived on June 10, 2012 form http:/quickfacts.census.gov/qfd/states/44000.html

Ventura, A. K., \& Birch, L. L. (2008). Does parenting affect children's eating and weight status? International Journal of Behavioral Nutrition and Physical Activity, 5(15). doi:10.1186/1479-Received

Ventura, A. K., Gromis, J. C., \& Lohse, B. (2010). Feeding practices and styles used by a diverse sample of low-income parents of preschool-age children. Journal of Nutrition Education and Behavior, 42(4), 242-249.

Wallston, B. S., Wallston, K. A., Kaplan, G. D., \& Maides, S. A. (1976). Development and validation of the health locus of control (HLC) scale. Journal of consulting and clinical psychology, 44(4), 580.

Webber, L., Hill, C., Cooke, L., Carnell, S., \& Wardle, J. (2010). Associations between child weight and maternal feeding styles are mediated by maternal perceptions and concerns. Eurpoean Journal of Clinical Nutrition, 64(3), 259265. doi:10.1038/ejen.2009.146.Associations 
Weiss, L. H., \& Schwarz, J. C. (1996). The relationship between parenting types and older adolescents' personality, academic achievement, adjustment, and substance use. Child development, 67(5), 2101-14.

Wieting, J. M. (2008). Cause and effect in childhood obesity: Solutions for a national epidemic. The Journal of the American Osteopathic Association, 108(10), 545-52.

Ystrom, E., Barker, M., \& Vollrath, M. E. (2012). Impact of mothers' negative affectivity, parental locus of control and child-feeding practices on dietary patterns of 3-year-old children: The MoBa Cohort Study. Maternal \& Child Nutrition, 8(1), 103-14. doi:10.1111/j.1740-8709.2010.00257.x 